\title{
Squaring Circles: The Gap for Interdisciplinary Trainees in a Discipline-Driven Academy
}

\author{
Shannon L Sibbald ${ }^{1}, \mathrm{PhD}_{\text {, Leslea Peirson }}^{2}$ \& Jennifer Boyko ${ }^{1}$ \\ 1 School of Health Studies, Faculty of Health Sciences, Department of Family Medicine, Schulich School of \\ Medicine and Dentistry, The Schulich Interfaculty Program in Public Health, Schulich School of Medicine and \\ Dentistry, Western University, Canada \\ 2 McMaster Evidence Review and Synthesis Centre, School of Nursing, McMaster University, Canada \\ Correspondence: Shannon L Sibbald, PhD, Assistant Professor, School of Health Studies, Faculty of Health Sciences, \\ Department of Family Medicine, Schulich School of Medicine and Dentistry, The Schulich Interfaculty Program in \\ Public Health, Schulich School of Medicine and Dentistry, Western University, Canada. E-mail: ssibbald@uwo.ca
}

Received: April 2, 2015

doi:10.5430/ijhe.v4n3p63
Accepted: June 5, 2015

Online Published: June 23, 2015

\begin{abstract}
The growth of interdisciplinary health services research training programs across Canada has in part been due to acknowledgement of and efforts to bridge a gap between researchers, policy makers and practitioners. Consequently, a new breed of interdisciplinary health services researchers (many of whom have specialization in knowledge translation) are now ready to meet complex system demands only to find limited career opportunities. We argue that the investments for advancing interdisciplinary health services training have not been paralleled with post-training positions in academia and elsewhere, and change must occur.
\end{abstract}

Keywords: Interdisciplinary, Training, Health services, Multidisciplinary, Collaboration, Education

\section{Introduction}

Bridging knowledge gaps by forging interdisciplinary partnerships is a topic of contemporary discussion, as is the focus on developing effective strategies for knowledge sharing within and between research and practice teams (Russell, Greenhalgh, Boynton, \& Rigby, 2004). We share Aboelela et al.'s (2007) definition of interdisciplinary research as "any study or group of studies undertaken by scholars from two or more distinct scientific disciplines" (p.341). Aboelela et al. (2007) further describe interdisciplinary research as being "based upon a conceptual model that links or integrates theoretical frameworks" and "requires the use of perspectives and skills of the involved fields throughout multiple phases of the research process" (p.341). Interdisciplinary health researchers actively participate in this type of research and work to bridge research, policy and practice. The increased emphasis on integrative collaboration has led to the creation of interdisciplinary health services training programs that aim to build capacity in knowledge translation research and practice (Curran, Grimshaw, Hayden, \& Campbell, 2011). A challenge arises in how we educate emerging researchers who can both identify with a particular health discipline and think systematically and critically across disciplines. We contend that a problem lies in: a) the recent increase in post-graduate interdisciplinary health services training programs; and b) the structure of academia, which has led to both the positioning of these programs within well-defined academic faculties and a lack of appropriate reward/incentive for implementing an interdisciplinary approach in practice. As a result of these challenges, opportunities for emerging interdisciplinary health services researchers are lacking and this paper argues that change is necessary.

\section{Interdisciplinary Collaboration - A Brief Literature Review}

Interdisciplinary collaboration has emerged as an important new priority for research institutions and their funding sources, as it appropriately equips researchers to tackle complex health issues that are rarely characterized by a single discipline (Choi \& Pak, 2006). Further, with regards to knowledge translation in decision-making processes, it has been suggested that the involvement of interdisciplinary committees is necessary to facilitate effective partnerships between researchers and policy makers in solving societal problems (Gagliardi et al., 2014).

Undertaking successful interdisciplinary collaboration is a learned skill, which depends on the development and mastery of several core competencies by the involved researchers (Gebbie et al., 2008). For example, the ability to 
share research from a specific discipline in language meaningful to an interdisciplinary team is one of these competencies that must be learned. This suggests a necessity for specific training programs aimed at supporting the development of interdisciplinary research skills. Although a significant need for new strategies to prepare faculty for interdisciplinary research has been acknowledged, the demand is scarcely being met (Larson \& Begg, 2011). Nevertheless, drawing from limited accounts of available interdisciplinary training programs, the experiences of interdisciplinary health services trainees contribute notable insights to the literature. Some trainees have brought their perspectives to light in meeting reports, through descriptions of their experiences in research and with collaboration building (Kho, Estey, DeForge, Mak, \& Bell, 2012; Urquhart, Johnston, McVorran, \& Burge, 2010; Cornelissen et al., 2011). Despite the contributions that health services trainees have made and other conversations about capacity building in health services and policy research in the literature, there appears to be a void in consensus and action to move forward (Born et al., 2010; Dicenso et al., 2009). A major obstacle to collaboration between scholars and practitioners identified in the literature is a lack of institutional incentives or recognition for these efforts (Gagliardi et al., 2014). According to Armstrong (2006), the traditional structures, organizational matrix, and culture of university faculties and departments have all acted as barriers to the enhancement of interdisciplinary health research. Investments in interdisciplinary health services training must be matched with investments in developing, sustaining and nurturing appropriate and sufficient changes in the academic structure in order to optimize interdisciplinary collaboration efforts.

\section{The Structure of Academia}

Academia is generally organized according to disciplines, each promoting preferred theories and methodologies, as well as merit and reward systems (Hall et al., 2006). As a result, while some universities offer interdisciplinary programs, courses and mentoring are usually provided by discipline-specific trained faculty; it is less common to find interdisciplinary trained faculty providing interdisciplinary training (Golding, 2009). As a result, interdisciplinary health services researchers may emerge from graduate programs with a distinct disciplinary focus. While it is possible to pursue interdisciplinary training without a core discipline, doing so often brings further challenges in pursuing discipline-specific work (e.g., faculty positions, funding/grants, tenure).

It is common for new $\mathrm{PhDs}$ to pursue further training through post-doctoral fellowships in order to advance their knowledge and skills (Mangematin, 2000 Lavis, Robertson, Woodside, McLeod, \& Abelson, 2003). Post-doctoral trainees can be fellows or associates, and they can be funded within a university or from an external award or salary grant. Universities and granting agencies have varying definitions, associated regulations, and policies to reflect the roles of post-doctoral fellows, associates, and scholars; however, for our purposes, we consider these terms synonymous, and we will mostly use the term post-doctoral fellow. For some health services graduates, post-doctoral training has become a necessary, but not sufficient, step toward an academic career. While there is a large number of faculty on the cusp of retirement, there is also a worrying trend to rely on part-time/contract appointments (Maldonado, Wiggers, \& Amold, 2013). The problem may resolve in a few years as a matter of natural workplace evolution; however, the larger issue for interdisciplinary health services researchers is whether these positions will be replaced with discipline-specific faculty.

\section{Interdisciplinary Health Services Research Training}

Our collective experience has shown that many established health services researchers who identify as interdisciplinary were trained in one discipline (e.g., nursing, occupational therapy, medicine) and garnered interdisciplinary skills mid-career. Graduate-level programs that focus on interdisciplinary health services research and practice are a relatively new phenomenon. One example of such a program is integrated into the School of Nursing at Columbia University. The program, open to post-doctoral candidates in any field of study, aims to better immerse students in interdisciplinary experiences (Larson, Cohen, Gebbie, Clock, \& Saiman, 2011). In Canada, interdisciplinary health services research training programs have also been developed in an effort to address the challenges of integrating disciplines and bridging research, policy and practice. For example, the Ontario Training Centre in Health Services and Policy Research is a consortium of six Ontario universities established to facilitate the involvement of more interdisciplinary health services researchers in addressing critical issues in effective and efficient health care delivery. In these graduate-level programs, trainees from a range of professional backgrounds learn how to think multidimensionally and work collaboratively to address health services and policy research questions. Funding opportunities (grants for training) are also on the rise for interdisciplinary trainees in North America: The Strategic Training Initiative in Health Research (STIHR) implemented by the Canadian Institutes of Health Research (CIHR) and the National Institutes of Health's (NIH) Training for a New Interdisciplinary Research Workforce (T90) are two such examples. Further, in the United Kingdom, Britain's Medical Research Council has 
responded to the growing desire for interdisciplinary collaboration by fostering the "highest quality multidisciplinary research programmes" through their 2015 grants competitions (Department for Business Innovation \& Skills, 2014). Post-graduate interdisciplinary training programs and fellowships also exist for individuals who are already trained in one discipline and are seeking further interdisciplinary expertise in health services research. One example is the Executive Training for Research Application (EXTRA) fellowship, funded and operated through the Canadian Foundation for Healthcare Improvement, which supports teams of health leaders to facilitate better management and use of evidence to improve the overall quality of healthcare. Another example is Ontario's Transdisciplinary Understanding and Training on Research - Primary Health Care (TUTOR-PHC) program, which aims to increase the interdisciplinary focus in primary health care research. In the United States, 41 institutions have developed interdisciplinary research career development programs with funding from the NIH and the Office of Research on Women's Health, through a mechanism titled "Building Interdisciplinary Research Careers in Women's Health (BIRCWH)" (Domino, Bodurtha, \& Nagel, 2011). For health services researchers with an interest in knowledge translation, the annual Knowledge Translation Canada Summer Institute (funded by the CIHR and Canadian Foundation for Innovation) provides an opportunity for aspiring investigators (including graduate students and post-doctoral fellows) from various academic backgrounds to build conceptual and applied capacity and to foster a network of like-minded scholars.

The introduction of these training opportunities, among others, represents an important change in response to the evidence that interdisciplinary research is vital to answering complex health questions and requires a learned skillset in order to be effectively undertaken. However, a problem exists in the lack of suitable opportunities for these trainees to apply their skills post-graduation. The question lies in why academia shapes interdisciplinary researchers like "round pegs" that are flexible, transferable and adaptable, but expects them to fit into existing "square holes," find new homes, or take on positions that are not appropriate to the acquired training and skills. Without altering the overarching academic system, the creation of training opportunities only partially addresses the present issue of incompatibility.

\section{Shifting Reality}

After completing graduate training, many graduates enter the labor force; however, there are fewer opportunities (academic or otherwise) for newly trained health services researchers (Lavis et al.,2003). While the surplus of PhDs is a global challenge, researchers without a core discipline are often at a further disadvantage because they do not meet the specific requirements (e.g., licensure) for faculty vacancies within schools that have a disciplinary focus (Desjardins, 2012). Evidently, there is a gap between what health services researchers say is needed (more interdisciplinary training) and how academia is currently designed (for individuals with expertise in specific disciplines). Health services trainees who have skills in boundary spanning and knowledge brokering and are competent in multi and interdisciplinary research methods are well suited for furthering important and timely research in academia. On the other side, these researchers are viewed as professionals who are better suited for work in policy making or service providing settings. As a result, interdisciplinary researchers are often kept at arm's length from both worlds. There are definite opportunities for scholars to span these domains, contributing to each and to both, to create real bridges between the worlds. It may be that interdisciplinary trainees do not belong in an existing piece of the system; perhaps, we need to evolve a new element tailored to what we bring and to who we serve and work alongside.

\section{Moving Forward}

The call from knowledge users and producers was clear: interdisciplinary boundary spanners are needed. Research institutions heard the call and introduced training (Greenhalgh \& Russell, 2006). However, simply offering training is an inadequate solution and universities and other institutions must catch up with the interdisciplinary way of thinking, without being limited to providing skills to out-going graduates. Collaborative efforts to explore and advance ways of integrating disciplinary fields of study and practice are missing (Urquhart et al., 2013). Interdisciplinary health services training was developed in part to respond to the lack of connection between knowledge producers and users; however, spanners span, they do not belong in one world or the other. There is a dissonance between what (or who) trainees have been groomed to be and the academic playing field that currently exists. Unless there are real intermediary roles without disciplinary expectations, the gap persists.

We believe academic, government and practice institutions must adapt in order to integrate this new type of researcher. Our experience tells us that individuals shaped to fill these roles are beginning to have increasing options, however few and far between they may be. We acknowledge that interdisciplinarity is primarily about relationships and the process of working together is one that researchers must evolve and adopt, but we also believe that there 
must be a more formal integration and application of these 'in-between' disciplinary positions (Nair, Dolovich, Brazil, $\&$ Raina, 2008). Innovative ways of integrating highly valued health services researchers into academic settings are needed (e.g., a position that is split between a university appointment and a practice setting). While examples of innovation are currently lacking, this should be an impetus for sparking change.

\section{References}

Aboelela S. W., Larson, E., Bakken, S., Carrasquillo, O., Formicola, A., Glied, S.A.,... Gebbie, K.M. (2007). Defining interdisciplinary research: Conclusions from a critical review of the literature. Health Services Research, 42(1), 329-46. http://dx.doi.org/10.1111/j.1475-6773.2006.00621.x

Armstrong, P.W. (2006). Advancing interdisciplinary health research: A synergism not to be denied. Canadian Medical Association Journal, 175(7), 761-762. http://dx.doi.org/10.1503/cmaj.060961

Born, K., Brown, A.D., Connell, K., Lewis, S., Mathews, M., \& Morgan, S. (2010, May 11). B6: PANEL - Horses for courses and courses for horses: A panel on HSPR capacity building. Proceedings of the 2010 Annual CAHSPR Conference, Toronto, ON: Canadian Association for Health Services and Policy Research.

Choi, B.C.K., \& Pak, A.W.P. (2006). Multidisciplinarity, interdisciplinarity and transdisciplinarity in health research, services, education and policy: 1. Definitions, objectives, and evidence of effectiveness. Clinical and Investigative Medicine, 29(6), 351-64.

Cornelissen, E., Urquhart, R., Chan, V.W., Deforge, R.T., Colquhoun, H.L., Sibbald, S., \& Witteman, H. (2011). Creating a knowledge translation trainee collaborative: From conceptualization to lessons learned in the first year. Implementation Science, 6(98), 1-5. http://dx.doi.org/10.1186/1748-5908-6-98

Curran, J.A., Grimshaw, J.M., Hayden, J.A., \& Campbell, B. (2011). Knowledge translation research: The science of moving research into policy and practice. Journal of Continuing Education in Health Professions, 31(3), 174-80. http://dx.doi.org/10.1002/chp.20124

Department for Business Innovation \& Skills. (2014). The allocation of science and research funding. Retrieved from

https://www.gov.uk/government/uploads/system/uploads/attachment_data/file/332767/bis-14-750-science-resear ch-funding-allocations-2015-2016-corrected.pdf

Desjardins, L. (2012). Profile and labour market outcomes of doctoral graduates from Ontario universities. Ottawa, ON: Statistics Canada, Higher Education Quality Council of Ontario; Report no.: 81-595-M. No. 98.

Dicenso, A., Phillips, K., Morgan, S., Boileau, L., \& Tamblyn, R. (2012, May 30). Dialogue on capacity building in health services and policy research: past, present and future. Proceedings of the CAHSPR Conference, Sub-Plenary, Montréal, Québec: Canadian Association for Health Services and Policy Research.

Domino, S.E., Bodurtha, J., \& Nagel, J.D. (2011). Interdisciplinary research career development: Building interdisciplinary research careers in women's health program best practices. Journal of Women's Health, 20(11), 1587-1601. http://dx.doi.org/10.1089/jwh.2011.3165

Gagliardi, A., Webster, F., Brouwers, M., Baxter, N., Finelli, A., \& Gallinger, S. (2014). How does context influence collaborative decision-making for health services planning, delivery and evaluation? BMC Health Services Research, 14(545), 1-12. http://dx.doi.org/10.1186/s12913-014-0545-x

Gebbie, K.M., Meier, B.M., Bakken, S., Carrasquillo, O., Formicola, A., Aboelela S.W., ... Larson, E. (2008). Training for interdisciplinary health research: Defining the required competencies. Journal of Allied Health, $37(2), 65-70$.

Golding, C. (2009). Integrating the disciplines: Successful interdisciplinary subjects. Melbourne, Victoria, Australia: Centre for the Study of Higher Education.

Greenhalgh, T., \& Russell, J. (2006). Promoting the skills of knowledge translation in an online master of science course in primary health care. The Journal of Continuing Education in the Health Professions, 26(2), 100-108. http://dx.doi.org/10.1002/chp.58

Hall, J.G., Bainbridge, L., Buchan, A., Cribb, A., Drummond, J., Gyles, C., ... Hicks, T.P. (2006). A meeting of minds: Interdisciplinary research in the health sciences in Canada. Canadian Medical Association Journal, 157(7), 763-771. http://dx.doi.org/10.1503/cmaj.060783

Kho, M.E., Estey, E.A., DeForge, R.T., Mak, L., \& Bell, B.L. (2009). Riding the knowledge translation roundabout: 
lessons learned from the Canadian Institutes of Health Research Summer Institute in knowledge translation. Implementation Science, 4(33), 1-7. http://dx.doi.org/10.1186/1748-5908-4-33

Larson E., \& Begg, M. (2011). Building interdisciplinary research models: A didactic course to prepare interdisciplinary scholars and faculty. Clinical and Transaltional Science, 4(1), 38-41. http://dx.doi.org/10.1111/j.1752-8062.2010.00258.x

Larson, E., Cohen, B., Gebbie, K., Clock, S., \& Saiman, L. (2011). Interdisciplinary research training in a school of nursing. Nursing Outlook, 59(1), 29-36. http://dx.doi.org/10.1016/j.outlook.2010.11.002

Lavis, J.N., Robertson, D., Woodside, J.M., McLeod, C.B., \& Abelson, J. (2003). How can research organizations more effectively transfer research knowledge to decision makers? The Milbank Quarterly, 81(2), 221-222. http://dx.doi.org/10.1111/1468-0009.t01-1-00052

Maldonado, V., Wiggers, R., Amold, C. (2013). So you want to earn a PhD? The attraction, realities, and outcomes of pursuing a doctorate. Toronto, ON: Higher Education Quality Council.

Mangematin, V. (2000). PhD job market: Professional trajectories and incentives during the PhD. Research Policy, 29(6), 741-756. http://dx.doi.org/10.1016/S0048-7333(99)00047-5

Nair, K.M., Dolovich, L., Brazil, K., \& Raina, P. (2008). It's all about relationships: A qualitative study of health researchers' perspectives of conducting interdisciplinary health research. BMC Health Services Research, 8(110), 1-10. http://dx.doi.org/10.1186/1472-6963-8-110

Russell, J., Greenhalgh, T., Boynton, P., \& Rigby, M. (2004). Soft networks for bridging the gap between research and practice: Illuminative evaluation of CHAIN. British Medical Journal, 328(7449), 1174. http://dx.doi.org/10.1136/bmj.328.7449.1174

Urquhart, A., Cornelissen, E., Lal, S., Colquhoun, H., Klein, G., Richmond, S., \&Witteman, H.O. (2013). A community of practice for knowledge translation trainees: An innovative approach for learning and collaboration. Journal of Continuing Education in the Health Professions, 33(4), 274-281. http://dx.doi.org/10.1002/chp.21190

Urquhart, R.L., Johnston, G.M., McVorran, S.M., \& Burge, F.I. (2010). Perspectives of an interdisciplinary research team to engage practice: Lessons from a knowledge exchange trainee experience. Healthcare Policy, 5(4), 47-57. $\mathrm{http}: / / \mathrm{dx}$. doi.org/10.12927/hcpol.2010.21782 